\title{
Analysis of Complications After Nephrectomy Using Modified Clavien-Dindo Classification- A Retrospective Study
}

\author{
T. Syama Sundara ${ }^{1}$, A. Tyagi ${ }^{2}$ \\ ${ }^{\prime}$ (Asst. Prof, Dept. of Urology, SVIMS, INDIA) \\ ${ }^{2}$ (Professor, Dept. of Urology, SVIMS, INDIA)
}

\begin{abstract}
There is a paucity of a standardized post-operative complications grading system in urology. The ClavienDindo classification is a simple, convenient, reproducible, comprehensive and logical system for postoperative complications and an established valid system worldwide and applicable in many fields of surgery. Using this we carried out a retrospective analysis of patients undergoing nephrectomy. We performed a retrospective review of patients who had undergone nephrectomy between may 2010 and may 2013 at our institute patients data was collected and analyzed with respective preoperative data and perioperative complications. Patients with comorbid illness were graded by Charlson comorbid index. Post-operative complications were graded according to the Clavien-Dindo classification. A total of 154 patients underwent nephrectomy during the study period. 32 patients had comorbid illness sand 112 patients without comorbidities.. 107 patients had a malignancy and 47 had benign diseases. Grade I, II, IIIa, IIIb, IV and V were 37.5\%, 42\%, 6.82\%, 7.97\%, $4.5 \%$ and $1.13 \%$ respectively. The Clavien-Dindo classification is easy to use and effectively applied to categorize post-operative complications after nephrectomy.
\end{abstract}

Keywords: BMI, clavien grading, comorbidities, complications, nephrectomy.

\section{Introduction}

Improving the quality of healthcare delivery system has been a subject of importance worldwide. A huge emphasis has been placed on reducing post-operative complications and thus reducing costs and improving the delivery of care. There is a paucity of reporting post-operative complications in urology. Complication rates are often used to compare the success of renal surgical techniques.

The reported incidence of complications in renal surgery ranges from 2- $54 \%$, irrespective of surgical approach $(10,11)$. In 1992, Clavien et al. proposed the Clavien classification system to grade post-operative complications (1,2). A modified version of the system (Clavien-Dindo), (Table 1) was published in 2004 which looked at the therapeutic consequences to rank complications $(3,4,5)$. The modified system is divided in to 7 grades (Grade I-V) with 2 subgroups for grade III and IV with grade V representing the death of a patient.

The Modified Clavien-Dindo classification is a simple, convenient, valid system used to grade the postoperative complications in many fields of surgery (6). The same classification system has recently been used by urologists to grade postoperative complications following radical prostatectomy, laparoscopic live donor nephrectomy, laparoscopic pyeloplasty, laparoscopic and open partial nephrectomy and most recently Transurethral Resection of Prostate $(7,8,9,10)$. Nephrectomy is the common major surgery in urology; henceforth we retrospectively analyzed our data in all patients who underwent nephrectomy.

Table1: Modified Clavien - Dindo grading system

\begin{tabular}{|l|l|}
\hline Grade I & $\begin{array}{l}\text { Any deviation from the normal postoperative course without the need for pharmacological } \\
\text { treatment or surgical, endoscopic and radiological interventions. Acceptable therapeutic regimens } \\
\text { are drugs such as antiemetics, antipyretics, analgesics, diuretics and electrolytes, and } \\
\text { physiotherapy. This grade also includes wound infections opened at the bedside. }\end{array}$ \\
\hline Grade II & $\begin{array}{l}\text { Requiring pharmacological treatment with drugs other than those allowed for grade I } \\
\text { complications. Blood transfusions and total parenteral nutrition are also included. }\end{array}$ \\
\hline Grade III & Requiring surgical, endoscopic or radiological intervention \\
\hline Grade III-a & Intervention not under general anaesthesia \\
\hline Grade III-b & Intervention under general anaesthesia \\
\hline Grade IV & $\begin{array}{l}\text { Life-threatening complication (including CNS complications: brain haemorrhage, ischaemic } \\
\text { stroke, subarachnoid bleeding, but excluding transient ischaemic attacks) requiring IC/ICU } \\
\text { management }\end{array}$ \\
\hline Grade IV-a & Single organ dysfunction (including dialysis) \\
\hline Grade IV-b & Multi-organ dysfunction \\
\hline Grade V & Death of a patient \\
\hline
\end{tabular}




\section{Materials And Methods}

We retrospectively analyzed patients who had undergone nephrectomy in SVIMS, Tirupathi, between May 2010 and May 2013. We included all patients undergoing open nephrectomy during the time period. The clinical data including age, gender, body mass index (BMI), Charlson comorbidity index (CCI), American Society of Anesthesiology Grade (ASA), operative time, blood loss and postoperative complications were analyzed.

The CCI was categorized, where minor comorbidities are defined as a CCI score of $<2$ and major comorbidities are $>2$. Complications occurring within 30 days postoperatively were noted. All complications were graded according to five grade modified Clavien- Dindo classification system.

All pathological data were collected. Data was recorded in an Excel spreadsheet, association of clavien grading and comorbidities were studied using chi-square analysis and Fischer exact tests. All P values were tailored and $\mathrm{P}<0.05$ was considered significant.

\section{Results}

154 patients were included in the study with mean age 62.4 (18-79), with 98 being male and 56 females (table 1). Transfusion rate was $8.2 \%$ with mean operative time $162 \mathrm{~min}$ (38-280). Patients with comorbidities were 42 and 112 without. Patients with CCI grade 1,2,3,4, 5 and > 6 seen in 24, 29, 3, 4, 1, 1 patients (table 3).

107 patients had malignancy with clear cell carcinoma most common (91.6\%) and 47 patients had benign pathology with stone with pelonephritis was common. Complications according to Clavien - Dindo classification include Grade I, II, IIIa, IIIb, IV and V were 37.5\%, 42\%, 6.82\%, 7.97\%, 3.42\%,1.13\% and $1.13 \%$ respectively (chart 1 ) with grade II complications were common. Wound infection was most common complication followed by anaemia. Death seen in 1 patient.

Patients with BMI >.25 had $57.4 \%$ of complications followed by BMI 18-25 had 30.3\% and BMI $<18$ had $12.3 \%$ (chart 2). Malignat patients with stage $>\mathrm{T} 2$ associated with more complications (chart 3). Patients with CCI more than 2 had more complications compared with CCI <2 (11.3\% vs 20.4\%) (Chart 4). Hospital was prolonged in patients with higher Clavien grades (chart 5).

Univariate analysis showed pathological $\mathrm{T}$ stage and comorbidites associated with statistically significant $(0.012,0.011)$, where as gender, age, BMI and simple with radical nephrectomy not significant(table $6)$.

Table 2: Analysis of patients' undergone nephrectomy

\begin{tabular}{|c|c|}
\hline Variable & Value \\
\hline Patients & 154 \\
\hline Mean Age & $62.4 \quad(18-79)$ \\
\hline Body mass index & $25.3 \quad(16-33)$ \\
\hline \multicolumn{2}{|l|}{ Gender } \\
\hline \multirow{2}{*}{$\begin{array}{l}\text { Male } \\
\text { Female }\end{array}$} & 98 \\
\hline & 56 \\
\hline ASA grade $>2$ & 28 \\
\hline Operative time & $162 \min (38-280)$ \\
\hline Blood loss & $450 \mathrm{ml} \quad(200-1300)$ \\
\hline No of pts received transfusion & $13 \quad(8.2 \%)$ \\
\hline Mean Transfusion volume & $495 \mathrm{ml}(330-1500)$ \\
\hline Hospital stay & $5.4 \quad(3-23)$ \\
\hline
\end{tabular}

Table 3: Charlson comorbidity index (CCI)

\begin{tabular}{|l|l|}
\hline Score & No of patients \\
\hline 0 & 92 \\
\hline 1 & 24 \\
\hline 2 & 29 \\
\hline 3 & 3 \\
\hline 4 & 4 \\
\hline 5 & 1 \\
\hline$>6$ & 1 \\
\hline
\end{tabular}


Table 4: Pathological status of Patients undergone Nephrectomy

\begin{tabular}{|l|l|l|}
\hline PATHOLOGICAL STATUS NO OF PTIENTS & \\
\hline BENIGN & 47 & 38.2 \\
\hline Stone with pyonephrosis, nephritis & 18 & 23.4 \\
\hline Neglected UPJO & 11 & 21.3 \\
\hline Chronic pyelonephritis & 10 & 10.6 \\
\hline Renal TB & 5 & 6.4 \\
\hline Others & 3 & \\
\hline MALIGNANT & 107 & 91.6 \\
\hline Clear cell & 98 & 4.7 \\
\hline Papillary & 5 & 0.94 \\
\hline Chromophobe & 1 & 1.87 \\
\hline Upper TCC & 2 & 0.94 \\
\hline Sarcoma & 1 & \\
\hline
\end{tabular}

Chart1: Complications according to Modified Clavien - Dindo grading system

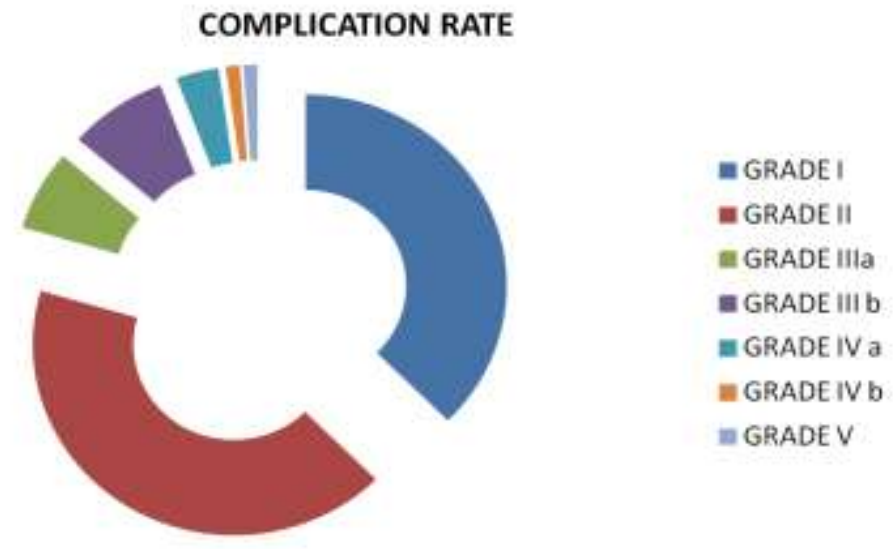

Table 5: Complications according to Modified Clavien -dindo grading system

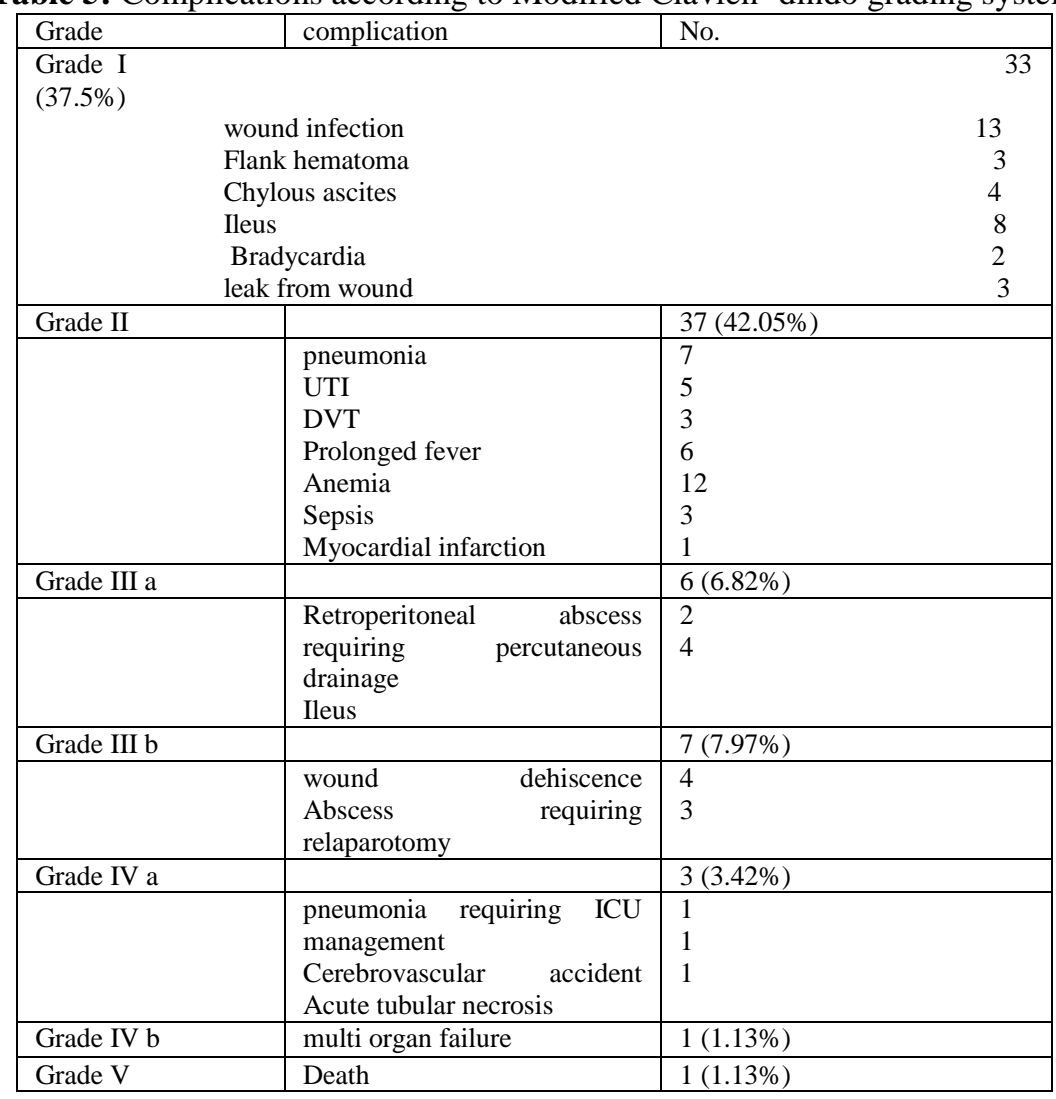


Chart 2: BMI and complication rates after Nephrectomy

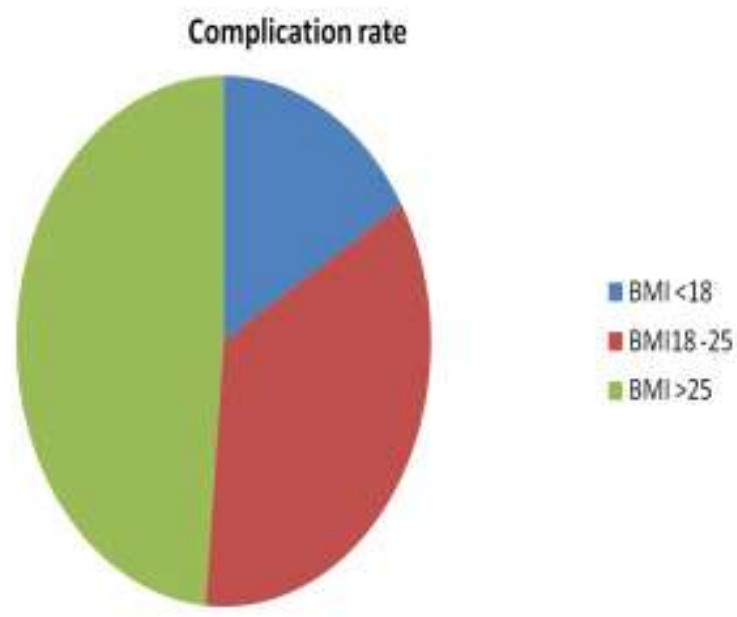

Chart 3: Complications according to Histological grades

\section{COMPLICATION RATE}

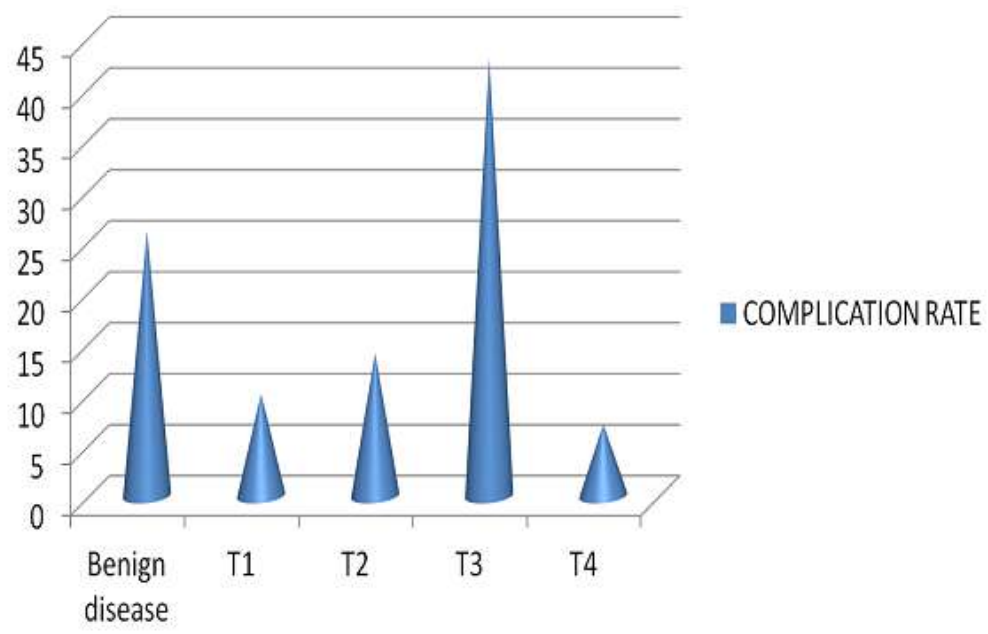

Chart 4: CCI with postoperative complications

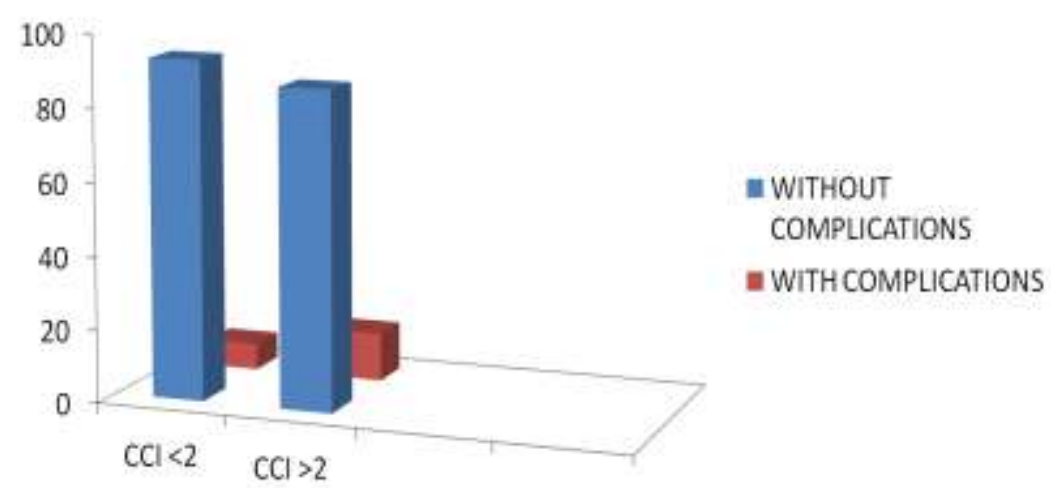




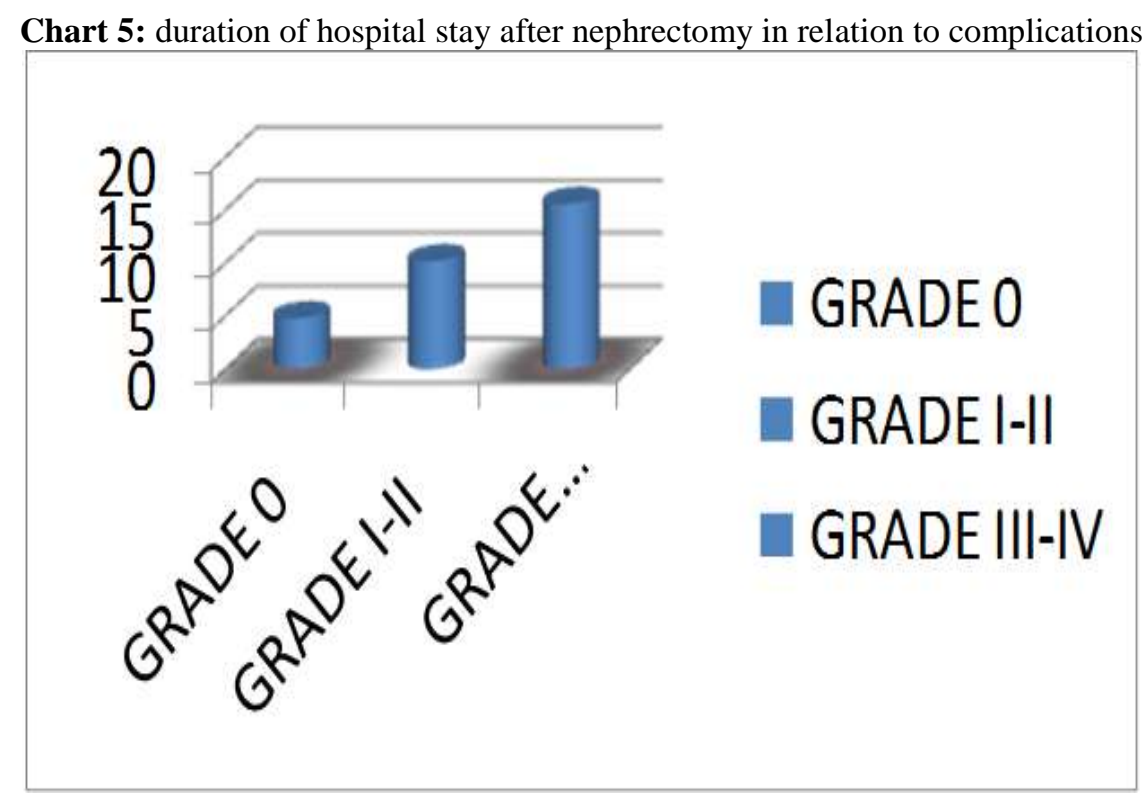

Table 6: Univariate analysis for prediction of complications according to modified clavien - dindo grading system

\begin{tabular}{|l|l|}
\hline Variable & P \\
\hline Pathological T stage & 0.012 \\
\hline Age & 0.349 \\
\hline Gender & 0.068 \\
\hline CCI & 0.011 \\
\hline Body mass index $(<25$ vs $>25)$ & 0.095 \\
\hline Simple vs radical nephrectomy & 0.212 \\
\hline
\end{tabular}

\section{Discussion}

Procedure specific complications are an important indicator for measuring quality in health care. Various studies have reported complications in kidney operations. Stephenson et al showed Overall 55\% and $31 \%$ of complications were grade I and grade II, respectively with $0.8 \%$ of deaths in a large cohort of 1049 patients after nephrectomy(12). Pauline et al showed overall complication rate of $34 \%$ with $64 \%$ grade I and II complications. Major complications were noted more in patients with major comorbidities (16\% vs7\%)(13). Our study showed total complication rate $46 \%$, mostly grade 2 complication accounting for overall $42.05 \%$ complications. Similarly, Grade 3 and 4 complications accounted for $14.77 \%$ and $4.55 \%$ respectively. Most common complications were wound infection, pneumonia and ileus. Minor complications are important as they cause prolonged hospital stay, morbidity to the patient.

In our study a higher BMI was associated with an increased percentage of complications, though not statistically significant. Kapoor et al. in their study demonstrated a longer operative time but comparable complications rate between obese and non-obese patients(18). In addition to comorbidities BMI was important risk factor for postoperative complications. Patients with CCI $>2$ associated with major complications when compared with patients with no complications $(13.2 \%$ vs $7.25 \%)$. Patients with major complications often associated with prolonged hospital stay. Patients with higher tumor grade (>T2) associated with major complication rate.

\section{Conclusions}

The Modified Clavien-Dindo classification is easy to use and effectively applied to categorize postoperative complications after nephrectomy. The most frequent complications were grade I and II. Major complications occur in patients with multiple comorbid diseases. Comorbid scores can be used in risk stratification of complications, hence can be considered during decision making and counseling of the patient before surgery. The surgery should be performed on selected patients with comorbid disease, and measures need to be taken to prevent these complications. 


\section{References}

[1]. Clavien PA, Sanabria JR, Strasberg SM. Proposed classification of complications of surgery with examples of utility in cholecystectomy. Surgery 1992;111:518-26.

[2]. Clavien PA, Barkun J, de Oliviera ML, Vauthey JN, Dindo D, Schulick RD, et al. The Clavien-Dindo classification of surgical complications: Five-year experience. Ann Surg. 2009;250:187-96.

[3]. Dindo D, Demartines N, Clavien PA. Classification of surgical complications: A new proposal with evaluation in a cohort of 6336 patients and results of a survey. Ann Surg. 2004;240:205-13.

[4]. Breitenstein S, DeOliveira ML, Raptis DA, Slankamenac K, Kambakamba P, Nerl J, et al. Novel and simple pre-operative score predicting complications after liver resection in non-cirrhotic patients. Ann Surg. 2010;252:726-34

[5]. Seely AJ, Ivanovic J, Threader J, Al-Hussaini A, Al-Shehab D, Ramsay T, et al. Systematic classification of morbidity and mortality after thoracic surgery. Ann Thorac Surg. 2010;90:936-42.

[6]. Tefekli A, Ali Karadag M, Tepelar K, Sari E, Berberoglu Y, Baykal M, et al. Classification of percutaneous nephrolithotomy complications using the modified clavien grading system: Looking for a standard. Eur Urol. 2008;53:184-90.

[7]. Zuazu JR, Hruza M, Rassweiler JJ, de la Rosette JJ. The Clavien classification system to optimize the documentation of PCNL morbidity. Arch Ital Urol, Androl. 2010;82:20-2.

[8]. Rabbani F, Yunis R, Pinochet L, Nogueira L, Vora KC, Eastham JA, et al. Comprehensive standardized report of complications of retro pubic and laparoscopic radical prostatectomy. Eur Urol.2010;57:371-86.

[9]. Loppenberg B, Noldus J, Holz A, Palisaar RJ. Reporting complications after open radical retro pubic prostatectomy using the Martin criteria. J Urol. 2010;184:944-8

[10]. Donat SM, Siegrist T, Cronin A, Savage C, Milowsky MI, Herr HW. Radical cystectomy in octogenarians--does morbidity outweigh the potential survival benefits? J Urol. 2010;183:2171-7.

[11]. Hsu TH, Gill IS, Fazeli-Matin S, Soble JJ, Sung GT, Schweizer D, et al. Radical nephrectomy and nephroureterectomy in the octogenarian and nonagenarian: Comparison of laparoscopic and open approaches. Urology. 1999;53:11215.

[12]. Sagrill D, Yap T, Durrant J, Anderson C, Rimington P, Rane A. Laparoscopy extirpative renal surgery in the octogenarian population. J Endourol. 2009;23:1499-502.

[13]. Thomas AA, Aron M, Hernandez AV, Lane BR, Gill IS. Laparoscopic partial nephrectomy in octogenarians. Urology. 2009;74:1042-6

[14]. Vasdev N, Hussein HK, Davidson A, Wood H, O'Riordan A, Soomro NA. Radical renal surgery (laparoscopic and open) in octogenerians. Surgeon. 2011;9:135-41. Epub 2010 Sep 23.

[15]. Pareek G, Yates J, Hedican S, Moon T, Nakada S. Laparoscopic renal surgery in the Octogenarians. BJU Int. 2008;101:867-70.

[16]. Gong EM, Orvieto MA, Lyon MB, Gong EM, Orvieto MA, Lyon MB, Lucioni A, Gerber GS, Shalhav AL et al. Analysis of impact of body mass index on outcomes of laparoscopic renal surgery. Urology. 2007;69:38-43.

[17]. Harper JD, Breda A, Leppert JT, Veale JL, Gritsch HA, Schulam PG. Experience with 750 consecutive patients laparoscopic donor nephrectomies-is it time to use a standardized classification of complications? J Urology 2010;183:1941-6.

[18]. Kapoor A, Nassir A, Chew B, Gillis A, Luke P, Whelan P, et al. Comparison of laparoscopic radical renal surgery in morbidly obese and non-obese patients. J Endourol. 2004;18:657-60.

[19]. 19.Bird VG, Shields JM, Aziz M, Ayyathurai R, De Los Santos R, Roeter DH. Laparoscopic radical nephrectomy for patients with T2 and T3 renal-cell carcinoma: Evaluation of perioperative complications. J Endourol. 2009;23:1527-33.

[20]. Murphy DG, Kerger M, Crowe H, Peters JS, Costello AJ. Operative details and oncological and functional outcome of roboticassisted laparoscopic radical prostatectomy: 400 cases with a minimum of 12 months follow-up. Eur Urol. 2009;55:1358-66.

[21]. Veen EJ, Steenbruggen J, Roukema JA. Classifying surgical complications: A critical appraisal. Arch Surg. 2005;140:1078-83.

[22]. Krupski TL. Standardization of reporting surgical complications: Are we ready? J Urol. 2010;183:1671-2.

[23]. Myatt A, Palit V, Burgess N, Biyani CS, Joyce AD. The Uro-Clavien-Dindo system - Will the limitations of the Clavien-Dindo system for grading complications of urological surgery allow modification of the classification to encourage national adoption within the UK? British J Med Surg Urol, 2012;5:54-60. 